\title{
Mortality league tables: do they inform or mislead?
}

\author{
Martin McKee, Duncan Hunter
}

\begin{abstract}
Objective-To examine certain methodological issues related to the publication of mortality league tables, with particular reference to severity adjustment and sample size.

Design-Retrospective analysis of inpatient hospital records.

Setting-22 hospitals in North West Thames health region for the fiscal year 1992-3.

Subjects-All admissions with a principal diagnosis of aortic aneurysm, carcinoma of the colon, cervical cancer, cholecystectomy, fractured neck of femur, head injury, ischaemic heart disease, and peptic ulcer.

Main measures-In hospital mortality rates adjusted by disease severity and calculated on the basis of both admissions and episodes.

Results-The numbers of deaths from specific conditions were often small and the corresponding confidence intervals wide. Rankings of hospitals by death rate are sensitive to adjustment for severity of disease. There are some differences that cannot be explained using routine data. Conclusions - Comparison of crude death rates may be misleading. Some adjustment for differences in severity is possible, but current systems are unsatisfactory. Differences in death rates should be studied, but because of the scope for manipulating data, this should be undertaken in a collaborative rather than a confrontational way. Any decision to publish league tables of death rates will be on political rather than scientific grounds.

(Quality in Health Care 1995;4:5-12)
\end{abstract}

Keywords: mortality, league tables, outcome measures

\section{Introduction}

A front page article in the Times in April 1993 described a sixfold variation in death rates among general surgical patients in English hospitals. ${ }^{1}$ The newspaper quoted experts, who argued that some of the variation reflected the competence of the surgeons concerned and the availability of resources. Reports such as this have stimulated the government to consider publication of league tables of hospital death rates. Their stated purpose is to provide information that will empower the public and purchasers of health care, thus enabling them to make more rational choices. Initial league tables, published in 1994, cover immediate assessment in accident and emergency departments, waiting in outpatient clinics, cancelled operations, arrival times of emergency ambulances, day surgery, and waiting times. Mortality rates were excluded for the time being, but after the publication of the first set of tables, there were many calls for them to be included in future. They have, however, been published in Scotland, and in the way that truancy and subsequently classroom time have been added to the initial examination success league tables in education, an extension of the health services tables in England and Wales to include mortality cannot be excluded.

In this paper we examine some of the methodological issues that arise in comparing hospital death rates. We examine in particular whether there is variation in crude in hospital mortality rates among providers in a region of a greater degree than might arise by chance; the effect of adjusting these rates for differences in patient characteristics, to the extent that this is possible using routine data; and other methodological issues that arise in comparisons.

\section{Methods}

We examined death rates by disease rather than by specialty or procedure. We did not look at specialty because of the considerable variation in types of cases treated within a particular specialty in different hospitals, and we did not look at procedures because of the possibility of introducing bias due to selection of patients for surgery. In consultation with regional clinical audit staff, eight conditions were selected for study. The criteria adopted by the regional staff were that they should be relatively common and that there had been previously voiced concern about differences in quality of care that might be explained by differences in mortality. The conditions were aortic aneurysm, carcinoma of the colon, cervical cancer, cholecystectomy, fractured neck of femur, head injury, ischaemic heart disease, and peptic ulcer. The study was based on routine Körner data from 22 acute hospitals in North West Thames region for the financial year 1992-3.

As each hospital treats patients with different probabilities of dying, data had to be adjusted for severity of case mix. Disease staging, a generic measure developed in the United States using routine American data, was used to calculate expected death rates. A detailed description of the disease staging system and an evaluation of its use in the United Kingdom is available elsewhere. ${ }^{2}$ Briefly, principal diagnoses are used to allocate a finished consultant episode to one or more of 400 
disease categories, such as those used in this study. Each disease category encompasses a range of principal diagnoses. The disease category derived from the first listed diagnostic code is designated the primary disease category. Within a disease category, an episode is then allocated to a stage, ranging from 0 to 3.9. Allocation to a high stage may be caused by the presence of a more severe principal diagnosis or the presence of certain secondary diagnoses, or a combination. For example, the presence of the code $574 \cdot 0$ (acute cholecystitis) will allocate an episode to disease category 708 "cholecystitis and/or cholelithiasis" and to stage $2 \cdot 2$ "acute cholecystitis." If, in addition, the code $576 \cdot 1$ "acute suppurative cholangitis" is present, the episode will be allocated to stage $3 \cdot 2$ "acute cholecystitis with acute suppurative cholangitis." The ranking of stages is ordinal, so that stage 2 is more severe than stage 1 but not twice as severe.

The British evaluation concluded that disease staging is clinically acceptable and valid, although the disease staging mortality scale, used in this study, had not then been available. This generates an expected death rate based on an algorithm developed using a multiple regression method with American hospital discharge data, incorporating combinations of primary disease categories and stages, comorbid conditions, method of admission, age and diagnosis related group.

For consistency, and as each condition may be represented by more than one code in the ninth revision of the International Classification of Diseases (ICD-9), conditions were defined as the group of ICD-9 codes contained in the disease categories of the same title used in the disease staging system. ${ }^{3}$ The analysis was undertaken in three phases.

Firstly, three parameters available from routine data that are used in the disease staging mortality scale were examined separately to see if they had an effect on the probability of death. These were the severity of disease, age, and whether the patient was admitted electively or as an emergency. The first was assessed in terms of disease stage, as described above.

Secondly, crude death rates were calculated for each disease category in each hospital. Hospitals with particularly high or low rates were then examined in greater detail to determine whether any of the parameters studied in phase 1 , or any other specific factors, could explain the observed variation.

Thirdly, the disease staging mortality scale developed for use with American data was examined to determine whether the scale, which combines the effect of the three parameters studied in phase 1 , reflected actual mortality rates in the United Kingdom. This was done by ascertaining whether the mean predicted mortality rate for each disease category, based on the whole sample, lay within the $95 \%$ confidence intervals for the actual rates.

In all cases confidence intervals of mortality rates were calculated assuming a binomial distribution. For the disease categories in which most rates were far from zero, the
Table 1 Percentage mortality by disease stage in 22 hospitals with numbers of episodes in parentheses

\begin{tabular}{lccc}
\hline Disease category & Stage 1 & Stage 2 & Stage 3 \\
\hline Head injury & $0 \cdot 7(4340)$ & $14 \cdot 9(170)$ & $4 \cdot 6(39)$ \\
Carcinoma of colon & $5 \cdot 8(3763)$ & $-{ }^{\star}$ & $10 \cdot 4(0131)$ \\
Peptic ulcer & $0 \cdot 9(2062)$ & $7 \cdot 6(368)$ & $10 \cdot 8(453)$ \\
Cholecystitis & $0 \cdot 4(2030)$ & $0 \cdot 6(925)$ & $5 \cdot 3(99)$ \\
Aortic aneurysm & $11 \cdot 8(268)$ & $-{ }^{\star}$ & $47 \cdot 4(189)$ \\
Carcinoma of cervix & $1 \cdot 2(2072)$ & $-\star$ & $29 \cdot 0(23)$ \\
Fractured neck of & $10 \cdot 0(2511)$ & $-\star$ & $17 \cdot 4(80)$ \\
$\quad$ femur & $3 \cdot 4(5924)$ & $5 \cdot 1(2059)$ & $20 \cdot 4(4738)$ \\
Ischaemic heart & & & \\
$\quad$ disease & & & \\
\hline
\end{tabular}

^Fewer than 10 cases.

standard formula was used, but for head injury, carcinoma of the cervix, cholecystitis, and peptic ulcer, where the observed rates were low and often included zero, the method of Fleiss was used. ${ }^{4}$ In the comparisons of all 22 hospitals $99 \%$ confidence intervals were chosen because of the multiple comparisons being undertaken as, with this number of comparisons, one hospital would be expected to seem significantly different by chance if $95 \%$ confidence intervals had been used. In comparisons of two hospitals $95 \%$ confidence intervals were used.

\section{Results}

ACCURACY OF DATA

The study did not seek to examine the quality of data in detail, but some observations were noted. Initially, we had intended to include data from 1991-2 to increase the sample size, but we decided against this because relatively complete data for this year were available from only 12 hospitals. In 1992-3 there were still many gaps, and in at least two hospitals there were substantial shortfalls of diagnostic codes. In one district general hospital episodes were only in the disease category ischaemic heart disease. In another hospital there were no episodes bearing the code for discharge methods that signified death, although other values were coded. Thus deaths could not be identified in that hospital.

IMPACT OF DISEASE SEVERITY, AGE, AND MODE OF ADMISSION ON PROBABILITY OF DEATH

There was clear association between disease stage and mortality for all disease categories (table 1). In almost all cases there was an increasing death rate with increasing stage. The exception was head injury. This is one of a number of disease categories known to exhibit this phenomenon due to selective transfer of the most seriously ill patients. It is also seen, typically, with major trauma and burns. ${ }^{5}$

There was also a clear association between method of admission and probability of death at each stage. The combined effects of stage and mode of admission can be seen clearly in the case of peptic ulcer (table 2). An association was also seen between age and the probability of death. This was also seen at all levels of severity of disease (table 3 ).

Although these results show a difference in the probability of death according to certain patient characteristics, this is only important if there are systematic differences in the 
Table 2 Percentage death rates by disease stage and method of admission for peptic ulcer. Numbers of episodes are in parentheses $\star$

\begin{tabular}{lcccc}
\hline & Stage 1 & Stage 2 & Stage 3 & Overall \\
\hline Elective & $0(1513)$ & $0 \cdot 8(61)$ & $3 \cdot 7(147)$ & $0 \cdot 2(1621)$ \\
Emergency & $3 \cdot 2(531)$ & $8 \cdot 3(301)$ & $11 \cdot 7(392)$ & $7 \cdot 2(1224)$ \\
\hline
\end{tabular}

${ }^{\star}$ Cases classified as other methods of admission or in which method of admission was uncoded are excluded.

Table 3 Percentage death rates by stage and age: peptic ulcer. Numbers of episodes are in parentheses

\begin{tabular}{llcll}
\hline Age (years) & Stage 1 & Stage 2 & Stage 3 & Overall \\
\hline $0-64$ & $0 \cdot 2(1222)$ & $0 \cdot 7(149)$ & $1 \cdot 9(211)$ & $0 \cdot 4(1582)$ \\
$65-75$ & $0 \cdot 2(402)$ & $5 \cdot 9(68)$ & $11 \cdot 6(86)$ & $2 \cdot 7(556)$ \\
$>75$ & $3 \cdot 4(438)$ & $15 \cdot 2(151)$ & $22 \cdot 4(156)$ & $9 \cdot 8(745)$ \\
\hline
\end{tabular}

distribution of these characteristics among hospitals. This was the case, with each characteristic varying considerably within each disease category (table 4), although at least some of this was probably due to coding errors, such as the relatively high proportions of elective admissions for head injury and fractured neck of femur in some hospitals. In some other cases the extreme values were associated with very small numbers.

The impact of differences in case mix can be seen in an examination of elective and emergency admissions, which were especially variable for ischaemic heart disease, peptic ulcer, carcinoma of the colon, and aortic aneurysm. Table 5 shows the death rates from carcinoma of the colon in two district general hospitals. Expected figures were calculated by applying the overall specific rates for mode of admission to the number of cases in each group. Hospital A had a lower crude death rate than hospital B. However, hospital B had a much higher proportion of emergency admissions. After adjustment for this, hospital $B$ seemed to be achieving better results than would be expected whereas hospital A was performing less well than expected, although it is not possible in this univariate analysis to eliminate confounding.

Table 4 Median percentages (ranges) of episodes with certain characteristics among hospitals

\begin{tabular}{|c|c|c|c|c|}
\hline & $\%$ Elective & $\begin{array}{c}\% \text { Aged } 75 \\
\text { or over }\end{array}$ & $\begin{array}{c}\text { \% Undergoing a } \\
\text { procedure }\end{array}$ & $\%$ In Stage 1 \\
\hline Head injury & $1 \cdot 8(0-22 \cdot 8)$ & $12 \cdot 0(4 \cdot 5-21 \cdot 0)$ & $11 \cdot 4(0 \cdot 7-21 \cdot 0)$ & $96 \cdot 7(87 \cdot 5-100)$ \\
\hline Carcinoma of colon & $66 \cdot 6(49 \cdot 1-100)$ & $35 \cdot 7(0-53 \cdot 8)$ & $72 \cdot 0(5 \cdot 0-100)$ & $83 \cdot 3(52 \cdot 1-100)$ \\
\hline Peptic ulcer & $56 \cdot 4(24 \cdot 7-97 \cdot 9)$ & $28 \cdot 7(13 \cdot 9-66 \cdot 7)$ & $88 \cdot 5(63 \cdot 9-100)$ & $73 \cdot 8(49 \cdot 6-100)$ \\
\hline Cholecystitis & $61 \cdot 8(0-96 \cdot 0)$ & $18 \cdot 3(0-34 \cdot 0)$ & $72 \cdot 4(50 \cdot 4-100)$ & $70 \cdot 3(24 \cdot 4-100)$ \\
\hline Aortic aneurysm & $40 \cdot 0(0-75 \cdot 4)$ & $47 \cdot 6(18 \cdot 2-100)$ & $64 \cdot 3(0-90 \cdot 9)$ & $52 \cdot 4(21 \cdot 4-87 \cdot 0)$ \\
\hline $\begin{array}{l}\text { Ischaemic heart } \\
\text { disease }\end{array}$ & $1 \cdot 7(0-88 \cdot 2)$ & $32 \cdot 1(4 \cdot 2-46 \cdot 4)$ & $(0-46 \cdot 4)$ & $3 \cdot 6(0 \cdot 4-90 \cdot 0)$ \\
\hline Carcinoma of cervix & $93 \cdot 2(25 \cdot 0-100)$ & $1.5(0-50 \cdot 0)$ & $96 \cdot 3(5 \cdot 6-100)$ & $99 \cdot 7(87 \cdot 5-100)$ \\
\hline $\begin{array}{l}\text { Fractured neck of } \\
\text { femur }\end{array}$ & $1 \cdot 2(0-13 \cdot 5)$ & $75 \cdot 6(60 \cdot 0-88 \cdot 2)$ & $89 \cdot 1(26 \cdot 7-93 \cdot 2)$ & $97 \cdot 3(88 \cdot 2-100)$ \\
\hline
\end{tabular}

Table 5 Effect of adjusting for mix of emergency and elective surgery for patients with carcinoma of colon in two neighbouring district general hospitals

\begin{tabular}{lcc}
\hline & $\begin{array}{c}\text { Hospital } A \\
(n=194)\end{array}$ & $\begin{array}{c}\text { Hospital B } \\
(n=1330)\end{array}$ \\
\hline \% Elective & 96.5 & 67 \\
\% Dead & $2 \cdot 8$ & $6 \cdot 2$ \\
Expected \% dead & $2 \cdot 5$ & $8 \cdot 8$ \\
Ratio of observed to expected & $1 \cdot 1$ & $0 \cdot 7$ \\
\hline
\end{tabular}

Table 6 Effect of adjusting for disease stage for patients with peptic ulcer in two neighbouring district general hospitals

\begin{tabular}{lcc}
\hline & Hospital A & Hospital B \\
\hline Overall \% dead & $4 \cdot 6$ & $4 \cdot 7$ \\
Stage 1\% dead (\% in stage) & $0(49 \cdot 6)$ & $2 \cdot 9(81 \cdot 6)$ \\
Stage 2\% dead (\% in stage) & $3 \cdot 7(20 \cdot 6)$ & $10 \cdot 7(10 \cdot 9)$ \\
Stage 3\% dead (\% in stage) & $12 \cdot 8(29 \cdot 8)$ & $15 \cdot 8(7 \cdot 5)$ \\
Expected \% dead & $5 \cdot 2$ & $2 \cdot 4$ \\
Ratio of observed to expected & $0 \cdot 9$ & $2 \cdot 0$ \\
\hline
\end{tabular}

A similar effect can be seen in a comparison of two other neighbouring district general hospitals that had similar crude death rates from peptic ulcer, but hospital A had a much higher proportion of cases in stage 3 (table 6). The death rates within each mode of admission and age group were similar.

\section{COMPARISON OF CRUDE DEATH RATES}

Crude death rates in each hospital, ranked in terms of increasing numbers of episodes, are shown in figure 1 . In some cases the number of hospitals is less than 22 because there were no cases in one or more hospitals.

Carcinoma of cervix, cholecystitis, peptic ulcer The numbers of episodes were very small and consequently the confidence intervals overlap in the cases of carcinoma of the cervix, cholecystitis, and peptic ulcer. As a result, it is impossible to identify any hospital justifying further investigation on the basis of these data.

\section{Fractured neck of femur}

Although the confidence intervals were narrower, there was little variation in death rates, with the exception of hospital 8 , which seemed to have a death rate significantly higher than the others. This was examined further by comparing it with a neighbouring hospital with apparently similar characteristics, including catchment area. The reason for the difference was not apparent from further analysis of the data (table 7) and suggests the need for a more detailed study of the process and outcome of care in that hospital.

\section{Ischaemic heart disease}

There was considerable variation in death rates for ischaemic heart disease, but this disease category contains a heterogeneous mix of cases, ranging from stable angina (stage 1) and unstable angina (stage 2) to myocardial infarction (stage 3 ). Because of this, myocardial infarctions were examined separately and, in this case, there was less variation (fig 2 ).

Table 7 Percentage death rates from fractured neck of femur by patient characteristics in two neighbouring hospitals

\begin{tabular}{lcc}
\hline & Hospital A & Hospital B \\
\hline Age (years): & & \\
$0-64$ & 0 & 0 \\
$65-74$ & $18 \cdot 8$ & $4 \cdot 2$ \\
$75-84$ & $26 \cdot 9$ & $2 \cdot 1$ \\
$\geqslant 85$ & $32 \cdot 4$ & $12 \cdot 8$ \\
Stage 1 & $26 \cdot 0$ & $5 \cdot 8$ \\
Stage 3 & 100 & 0 \\
Surgery & $23 \cdot 7$ & $6 \cdot 7$ \\
No surgery & $50 \cdot 0$ & $5 \cdot 6$ \\
\hline
\end{tabular}


Aortic aneurysm and carcinoma of colon

There were definite trends in the cases of aortic aneurysm and carcinoma of the colon. In both there was evidence of a relation between volume and outcome, with an apparent reduction in death rates at above 30 and 400 episodes per year respectively. This can be seen more clearly by plotting the number of
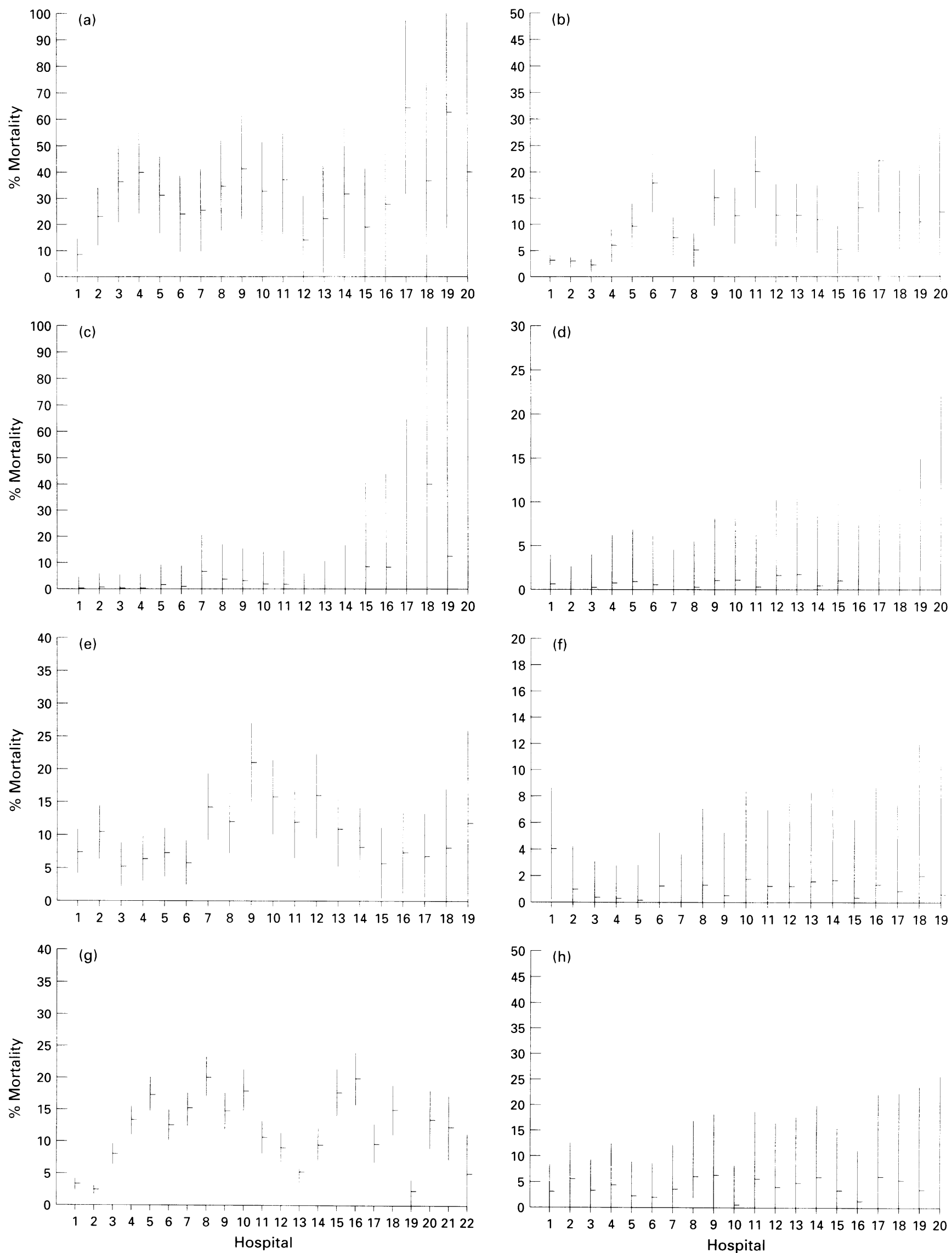

Fig 1 Rankings, in order of increasing number of episodes, of crude death rates by hospital: (a) aortic aneurysm, (b) carcinoma of colon, (c) carcinoma of cervix, (d) cholecystitis, (e) fractured neck of femur, (f) head injury, $(g)$ ischaemic heart disease, ( $h$ ) peptic ulcer 


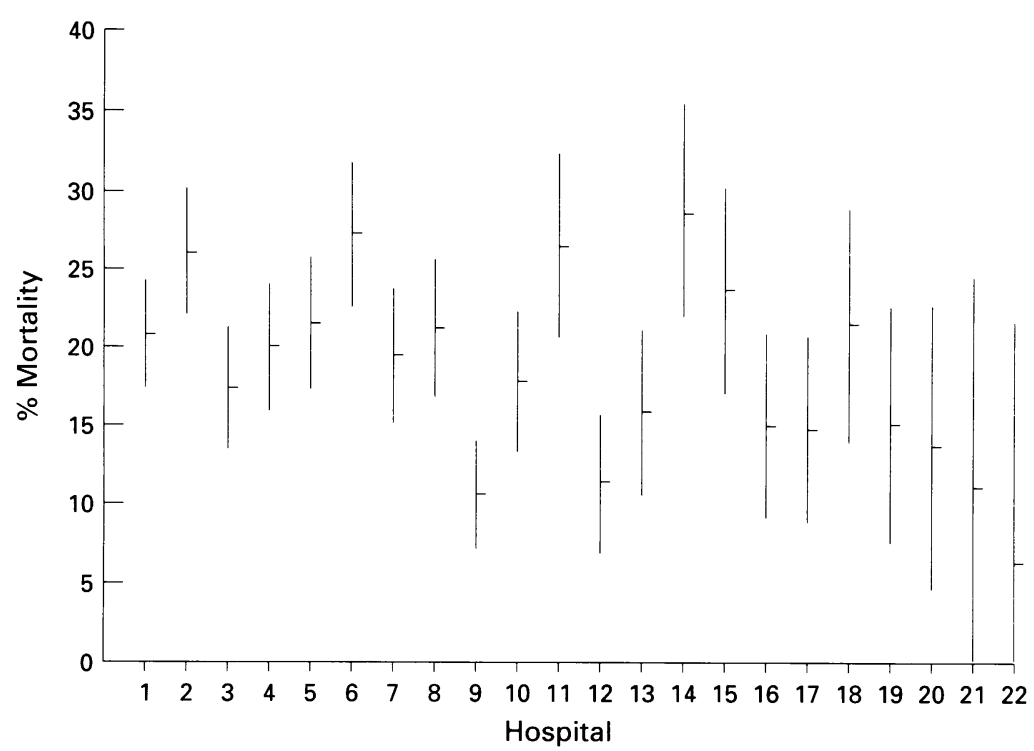

Fig 2 Ranking, in order of number of episodes, of crude death rates by hospital for myocardial infarction
Table 8 Percentage death rates from aortic aneurysm by patient characteristics in two similar hospitals with numbers of episodes in parentheses

\begin{tabular}{|c|c|c|}
\hline & Hospital $A$ & Hospital B \\
\hline Overall & $11 \cdot 5(61)$ & $25 \cdot 6(39)$ \\
\hline Stage 1 & $10 \cdot 2(49)$ & $12 \cdot 5(24)$ \\
\hline \multirow{2}{*}{\multicolumn{3}{|c|}{ Age (years): }} \\
\hline & & \\
\hline $\begin{array}{l}0-64 \\
65-74\end{array}$ & $0(14)$ & $14 \cdot 3(7)$ \\
\hline $\begin{array}{l}65-74 \\
\geqslant 75\end{array}$ & $12 \cdot 1(33)$ & $20 \cdot 0(15)$ \\
\hline$\geqslant 75$ & $21 \cdot 4(14)$ & $35 \cdot 3(17)$ \\
\hline Emergency ${ }^{\star}$ & $18 \cdot 2(46)$ & $38 \cdot 1(21)$ \\
\hline Elective ${ }^{\star}$ & $8.7(11)$ & $0(12)$ \\
\hline Surgery & $11 \cdot 1(52)$ & $41 \cdot 7(27)$ \\
\hline No surgery & $11.5(9)$ & $18.5(12)$ \\
\hline
\end{tabular}
method of admission was uncoded are excluded.

other with a high rate (hospital B) (table 9). Again, the routine data suggest that the effect of clinical volume is independent of other factors.

\section{Head injury}

There was little difference between hospitals with the notable exception of hospital 1 , which is a regional neurosurgical referral centre.

episodes against death rates (figs 3 and 4 ). The nature of the relation differs, with an apparent threshold effect for carcinoma of the colon but an apparent linear relation with aortic aneurysm.

In the case of aortic aneurysm, a comparison of hospitals 1 and 2 in figure 1 suggests that the effect seemed to be independent of severity or mode of admission (table 8 ), with hospital 1 achieving consistently lower death rates. These hospitals are both teaching hospitals.

Similar findings were obtained for carcinoma of the colon from a comparison of two hospitals, one with a low (hospital A) and the

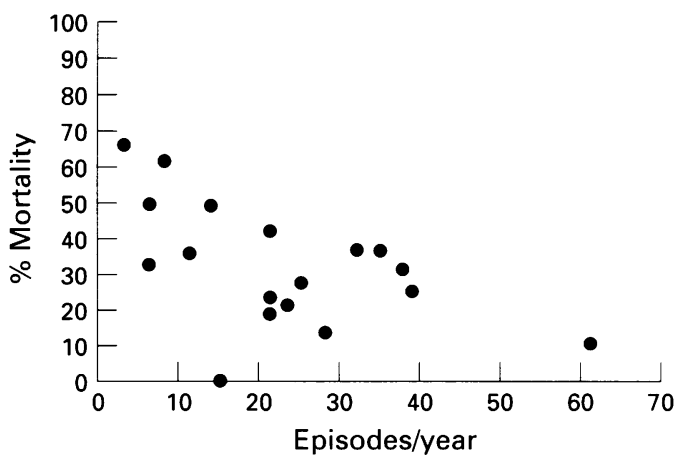

Fig 3 Relation between volume and outcome for aortic aneurysm

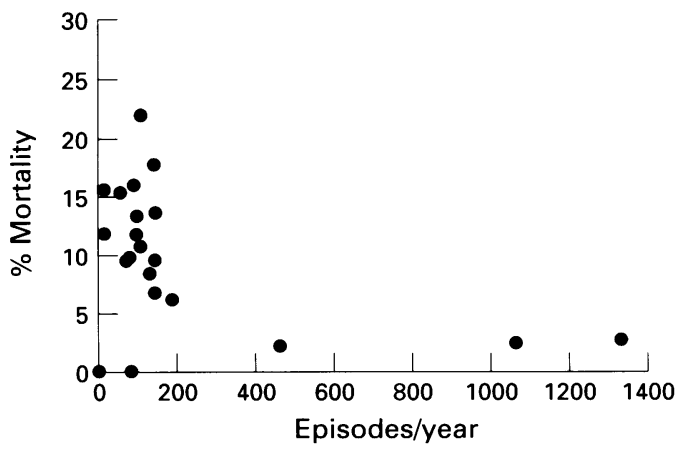

Fig 4 Relation between volume and outcome for carcinoma of colon

\section{QUALITY OF CODING}

Measurement of the severity of disease is dependent on the quality of coding. One hospital was observed consistently to have much higher death rates than expected on the basis of the disease staging scale. The ratio of observed to expected rates in this hospital (designated hospital $\mathrm{A}$ ) and a neighbouring and otherwise similar hospital (hospital B) are shown in table 10. The difference was greatest for the disease categories in which progression to a higher stage was due mainly to the presence of secondary diagnoses rather than to a different principal diagnosis. Further examination confirmed that hospital $\mathrm{A}$ had an extremely low level of coding of secondary (table 11).

Table 9 Percentage death rates from carcinoma of colon by patient characteristics in two similar hospitals with numbers of episodes in parentheses

\begin{tabular}{lcc}
\hline & Hospital A & Hospital B \\
\hline Overall & $6 \cdot 2(194)$ & $17 \cdot 7(147)$ \\
Stage 1 & $5 \cdot 9(152)$ & $15 \cdot 1(126)$ \\
Stage 3 & $7 \cdot 1(42)$ & $33 \cdot 3(21)$ \\
Age (years): & & \\
$0-64$ & $4 \cdot 1(49)$ & $8 \cdot 0(46)$ \\
$65-74$ & $1 \cdot 3(75)$ & $8 \cdot 8(31)$ \\
$\geqslant 75$ & $12 \cdot 9(70)$ & $30 \cdot 2(44)$ \\
Emergency & $14 \cdot 3(63)$ & $34 \cdot 5(55)$ \\
Elective & $1 \cdot 5(130)$ & $6 \cdot 6(91)$ \\
Surgery & $2 \cdot 2(138)$ & $6 \cdot 6(106)$ \\
No surgery & $16 \cdot 1(56)$ & $46 \cdot 3(41)$ \\
\hline${ }^{\star}$ Cases
\end{tabular}

${ }^{\star}$ Cases classified as other methods of admission or in which method of admission was uncoded are excluded.

Table 10 Ratio of observed to expected death rates in two hospitals

\begin{tabular}{lcc}
\hline & Hospital A & Hospital B \\
\hline Head injury & 4.69 & 0.97 \\
Carcinoma of colon & $1 \cdot 14$ & 1.08 \\
Peptic ulcer & 3.82 & 1.73 \\
Cholecystitis & $2 \cdot 87$ & 1.02 \\
Aortic aneurysm & $2 \cdot 24$ & 0.77 \\
Carcinoma of cervix & 0 & 3.9 \\
Fractured neck of femur & 3.97 & 0.99 \\
Ischaemic heart disease & 0.81 & 0.66 \\
\hline
\end{tabular}
diagnoses compared with other hospitals 
Table 11 Percentage of diagnostic code slots containing code: comparison of hospital $A$ with all other hospitals

\begin{tabular}{lcc}
\hline & Hospital A & All other hospitals \\
\hline Position 2 & $41 \cdot 0$ & $59 \cdot 5$ \\
Position 3 & $16 \cdot 6$ & $28 \cdot 4$ \\
Position 4 & $7 \cdot 9$ & $10 \cdot 9$ \\
Position 5 & $2 \cdot 7$ & $4 \cdot 1$ \\
Position 6 & $0 \cdot 4$ & $1 \cdot 4$ \\
Position 7 & $0 \cdot 1$ & $0 \cdot 4$ \\
\hline
\end{tabular}

Table 12 Comparison of actual and predicted mortality rates

\begin{tabular}{lccc}
\hline & $\begin{array}{c}\text { Actual death rate } \\
\text { (95\% confidence interval) }\end{array}$ & No of episodes & $\begin{array}{c}\text { Mean predicted mortality } \\
\text { (95\% confidence interval) }\end{array}$ \\
\hline Heady injury & $1 \cdot 3(1 \cdot 0$ to $1 \cdot 6)$ & 4549 & $2 \cdot 7(2 \cdot 2$ to $3 \cdot 2)$ \\
Carcinoma of colon & $6 \cdot 0(5 \cdot 3$ to $6 \cdot 7)$ & 4794 & $8 \cdot 1(7 \cdot 3$ to $8 \cdot 9)$ \\
Peptic ulcer & $3 \cdot 3(2 \cdot 6$ to $4 \cdot 0)$ & 2883 & $1 \cdot 9(1 \cdot 4$ to $2 \cdot 4)$ \\
Cholecystitis & $0 \cdot 7(0 \cdot 4$ to $1 \cdot 0)$ & 3054 & $0 \cdot 7(0 \cdot 4$ to $1 \cdot 0)$ \\
Aortic aneurysm & $28 \cdot 0(23 \cdot 9$ to $32 \cdot 1)$ & 457 & $21 \cdot 3(17 \cdot 5$ to $25 \cdot 1)$ \\
Ischaemic heart disease & $9 \cdot 2(8 \cdot 7$ to $9 \cdot 7)$ & 12721 & $3 \cdot 8(3.5$ to $4 \cdot 1)$ \\
Carcinoma of cervix & $1 \cdot 6(1 \cdot 1$ to $2 \cdot 1)$ & 2097 & $1 \cdot 8(1 \cdot 2$ to $2 \cdot 4)$ \\
Fractured neck of femur & $12 \cdot 6(11 \cdot 3$ to $13 \cdot 9)$ & 2592 & $3 \cdot 2(2 \cdot 5$ to $3 \cdot 9)$ \\
\hline
\end{tabular}

EXAMINATION OF THE AMERICAN DISEASE

STAGING MORTALITY SCALE

The 95\% confidence intervals for the actual mortality rate for each disease category and the mean value of the predicted mortality are shown in table 12 . In only three cases - aortic aneurysm, carcinoma of the cervix, and cholecystitis - did the $95 \%$ confidence intervals for the observed and predicted values overlap.

EPISODE INFLATION

Inflation of finished consultant episodes is recognised to have arisen as a consequence of the contracting system introduced in the 1990 NHS reforms. It occurs when a patient is transferred between consultants during an admission, accumulating episodes in the process. As episodes are used as the denominator in the calculation of death rates, an increase will have the effect of artificially decreasing the apparent death rate. The extent of episode inflation varied widely and in some hospitals the number of episodes and admissions were identical. In others, however, the effect was considerable. This is illustrated by the example of cholecystitis (fig 5 ).

\section{Discussion}

This study confirms the existence of considerable variation in death rates among hospitals. It also demonstrates the existence of

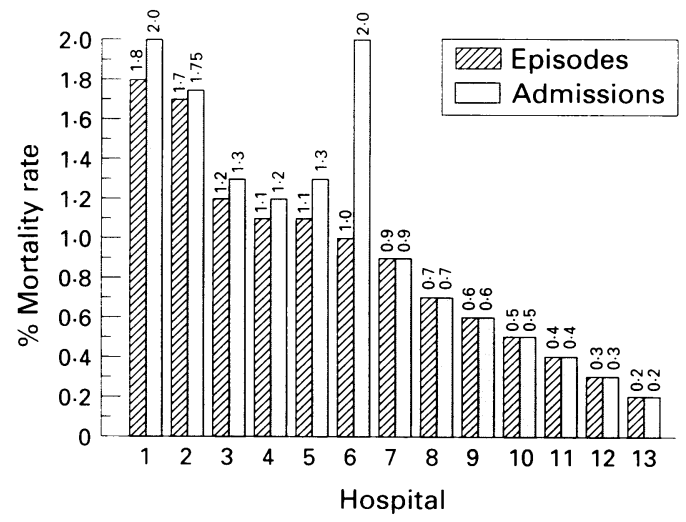

Fig 5 Effect of using numbers of episodes and admissions on in hospital mortality rates for cholecystitis variation in case mix, as far as can be ascertained from routine data, and highlights several factors of importance in the debate about publication of death rates by individual hospitals.

The first is that, when analysed by disease category and using data from one year, the sample sizes are often too small to enable meaningful conclusions to be drawn. Alternatives are problematic. Death rates by specialty would be meaningless because of differences in case mix. Examination of data from more than one year produces the problem of discerning the reasons for things that happened up to three years previously, by the time the data are available for analysis. Clearly, any attempt to analyse data relating to individual doctors would face even greater problems.

The second is that there is a need to adjust for case mix and this should include, at least, disease severity (however measured), age, and method of admission. Comparison of crude rankings can be highly misleading, with some hospitals that seem to perform well using crude rates appearing worse after adjustment for patient characteristics.

One way forward, examined in this study, is to compensate for differences in severity by adjusting on the basis of a composite figure incorporating disease stage, comorbidity, method of admission, and age. This is the approach used in the American disease staging severity scale. This study shows that the scale is valid in the United Kingdom only to the extent that the factors included are associated with differences in the probabilities of death. For six of the eight disease categories examined there was a significant difference between the predicted value and the actual one, when all hospitals in the region were included. This strongly suggests that the equations and weighting factors, generated from American data, are not valid in the United Kingdom. In the case of the disease categories studied, there are good reasons why this might be so. The much higher use of firearms in injuries in the United States is likely to lead to a greater severity of head injuries that would not necessarily be captured by routine data. The low predicted mortality from fractured neck of femur is probably due to the much shorter length of stay in the United States, given that the scale is based on in hospital mortality. In the United States, patients are transferred to nursing homes much sooner than in the United Kingdom. Although there is concern in the United Kingdom about "bed blocking" by these patients, there is a different concern in the United States because it is realised that an increasing proportion of those that would previously have been discharged home are remaining in nursing homes after one year. ${ }^{6}$ The lower mortality than predicted from carcinoma of the colon may be due to dilution of the case mix seen in the United Kingdom by large numbers of patients admitted for investigation who would be treated in ambulatory care in the United States. The higher death rates from peptic ulcer and 
ischaemic heart disease may be because of the lower frequency of secondary diagnoses in the United Kingdom, and especially those such as "fluid and electrolyte imbalance" that have the effect of placing patients in a more expensive diagnosis related group in the United States. This means that the British data underestimate the severity that would be recorded for the same patient in the United States, although this will probably change once contracting on the basis of healthcare resource groups is introduced in Britain.

These problems are also likely to exist with any similar scale based on American data. Thus, if such an approach is to be used a scale based on British data will need to be developed. Even if it is, however, considerable caution is required because of the limited extent to which any system for adjusting for severity on the basis of routine diagnostic data can adequately compensate for severity, ${ }^{7}$ especially given the inability of the International Classification of Diseases to capture important variations in clinical presentation ${ }^{8}$ and variations in the extent of coding of comorbidity.

The third is that there remain questions about whether the quality of coding is yet of sufficient quality to support adjustment for severity of this nature. Some hospitals with poor coding of secondary diagnoses will probably seem to be treating much less severe illness than is the case. Conversely, in the absence of clear and explicit guidelines on coding secondary diagnoses, it would be relatively easy for hospitals to increase the extent of coding beyond the norm in order to appear to have a more severe case mix than is the case. This would happen if they used the coding conventions currently used in the United States. Green and Wintfield have shown, in a study using California data, that errors in discharge data have a substantial effect on the calculation of expected mortality rates after adjustment for severity. ${ }^{9}$ Further work with some of the hospitals in this study will examine the extent to which death rates reflect differences in quality of care, although the experience of similar exercises in the United States is not encouraging. There it has not been possible to relate explicitly defined differences in quality of care to differences in death rates. ${ }^{10}$

The fourth is that the ambiguity about the finished consultant episode leaves considerable scope for opportunism, with both comparisons of death rates and the contracting process creating a strong incentive for episode inflation. A solution would be to examine data based on some other measure, such as provider spells. Unfortunately, this would preclude adjustment for severity because available diagnostic data relate to each episode and there is no obvious way to combine them in such a way that the principal reason for being in hospital throughout the entire spell could be identified. This problem is well recognised within the Department of Health and the NHS but is probably currently intractable, given the political opposition to changing the unit of currency from consultant episodes because of the effect on claims of greater activity after the introduction of the NHS reforms. ${ }^{11}$

Notwithstanding these problems, there are differences in death rates between hospitals that cannot be explained by known factors that can be ascertained from routine data. In some cases there are other, identifiable explanations. For example, for aortic aneurysm and carcinoma of the colon, hospitals with the highest volumes seemed to perform comparatively well. This is consistent with evidence for a volume-outcome relation for these conditions. ${ }^{12} 13$ This relation can take a variety of forms, depending on the condition being studied. ${ }^{14}$ The high death rate after head injury may have been due to selective transfer of the most severe cases from other hospitals, although it is not possible to prove this from the data. In other cases there remains the possibility that there may be real differences in quality of care. For example, in the hospital with a high mortality from fractured neck of femur, subsequent inquiry has revealed very poor cooperation between orthopaedic and geriatric medicine departments.

There are many other possible explanations for these differences that could not be examined with the available data. For example, some hospitals may have policies that lead to the admission of higher numbers of patients with cancer requiring palliative care, perhaps because of the absence of adequate provision of hospices locally. A suggestion to tackle this specific issue is the inclusion of a variable entitled "purpose of admission" to datasets, enabling such patients to be identified and excluded from analysis. ${ }^{15}$

Our study has shown the difficulty of comparing crude death rates. Their interpretation requires further detailed analysis and local knowledge; when death rates have been published in the United States, they have been accompanied by very detailed commentary and many caveats. The greatest concern about publication is the extent to which they may lead to changes in behaviour that are not in the patients' interest. ${ }^{16}$ Drawing on experience with performance indicators, Smith has described in detail the managerial responses to measures such as this. ${ }^{17}$ They include concentration on the topic being measured, to the exclusion of other more important areas, the pursuit of narrow objectives rather than coordination, concentration on short term issues, a disinclination to innovate, altering behaviour to gain strategic advantage, and fraud. Taking the last two only, the methodological points outlined above indicate how easy it would be to improve a hospital's results. Episode inflation will increase the denominator while the numerator remains the same. The extent to which clinical judgment can influence the allocation of diagnostic codes makes it comparatively easy to move patients from one diagnostic category to another. All severity systems using routine data have limited ability to identify true differences in severity so it may be advantageous to avoid treating patients who are seriously ill. Finally, 
there is considerable scope for misplacing the case notes of those patients who die, thus reducing the chances of them being entered on to the dataset. ${ }^{18}{ }^{19}$ It is naive to assume that publication of mortality league tables will not lead to changes in behaviour and data recording by providers. The introduction of prospective payment in the United States was associated with considerable changes in diagnostic coding, to the advantage of providers..$^{20}$ The use of finished consultant episodes in contracting in the United Kingdom has been associated with an increase in recording of episodes, with an apparent increase in activity. ${ }^{21}$ In other sectors, there is evidence of similar changes in behaviour and in data collection and definition - for example, schools judged on A level success rates refusing less able pupils entry to the exams and British Rail lengthening published journey times.

There is an argument that publication of league tables would force people to overcome these difficulties. This ignores the complexity of the methodological issues involved, but, given the prevailing philosophy, these problems are unlikely to prevent their publication. If they are to be published several steps must be taken before they can have any credibility. Firstly, there is a need for a severity adjustment scale based on British data. Secondly, the finished consultant episode must be replaced by an improved measure. Thirdly, there must be expansion of record linkage programmes. Finally, there must be a major investment in improvements in data quality. Some problems present greater difficulty. These include the small numbers involved and the potential for manipulation. Even if these problems could be resolved, the evidence from the United States is still far from clear whether observed differences in mortality actually reflect differences in quality of care.

Purchasing and clinical audit provide a means to examine these issues in a nonconfrontational fashion. Hospitals at either end of the spectrum of death rates from conditions that commonly lead to death - for example, fractured neck of femur - might undertake collaborative systematic reviews of case notes, extending the comparisons begun in this paper. For conditions from which death is rare, case notes could be reviewed in a confidential inquiry. Although deaths after surgery will already by examined in this way under the confidential enquiry into perioperative deaths programme, ${ }^{22}$ this does not apply to deaths from medical conditions. Similar issues are arising in the United States in relation to physician profiles. ${ }^{23}$ Publication of flawed data is likely to introduce a degree of confrontation that will reduce the probability of cooperation between providers and purchasers, with the possibility of adverse consequences for patient care.

This study was funded by North West Thames Regional Health Authority. We thank Alison Frater, Trevor Sheldon, Roy CarrHill, and Nick Freemantle for encouragement and advice, and Geoff Howard for providing the hospital data. The views expressed are ours alone.

Laurence J. Patients pay with their lives in operation "lottery". The Times. 1993 April 27: (col 1).

McKee M. Petticrew M. Disease staging: a case mix system for purchasers? F Public Health Med 1993;15:25-36.

3 Gonnella J, ed. Disease staging: clinical criteria, 3rd ed. Santa Barbara, CA: Systemetrics/McGraw Hill, 1989.

4 Fleiss JL. Statistical methods for rates and proportions. New York: Wiley, 1981: 15

5 McKee M, Petticrew M. An craluation of disease staging in the United Kingdom. Report to the National Case-mix Office. London: Department of Health, 1991

6 Gerety MB, Sodeholm-Difatte V, Wingrad CH. Impact of prospective payment and discharge location on the outcome of hip fracture. If Gen Intern Med 1989; 4:388-91

7 Ballard DJ, Bryant SC, O'Brien PC, Smith DW, Pine MB, Cortese DA. Referral selection bias in the Medicare hospital mortality prediction model: are centers of referral for Medicare beneficiaries necessarily centers of for Medicare beneficiaries necessarily
excellence? Health Serv Res 1994;28:771-84

8 Iezzoni LI. Using administrative diagnostic data to assess the quality of hospital care: pitfalls and potential of ICDthe quality of hospital care: pitfalls and potential of ICD
9CM. Int $₹$ Technol Assess Health Care 1990;6:272-81

9 Green J, Wintfield N. How accurate are hospital discharge data for evaluating effectiveness of care? Med Car 1993;31:719-31.

10 Park RE, Brook RH, Kosecoff J, et al. Explaining variations in hospital death rates: randomness, severity of illness, quality of care. $\mathcal{F A M A} 1990 ; 264: 484-90$

11 Mawhinney B. House of Commons official report (Hansard) 1993 January 14 ; col 806

12 Luft HS. The relationship between surgical volume and mortality: an exploration of causal factors and alternative models. Med Care 1980;18:940-59.

13 Luft HS, Bunker JP, Enthoven AC. Should surgical operations be regionalised: the empirical relation between
surgical volume and mortality. I Engl f Med surgical volume
1979;301:1364-9.

14 Black N, Johnston A. Volume and outcome in hospital care: evidence, explanations and implications. Health Ser Management Res 1990;3:108-14.

15 Iezzoni LI, Henderson MG, Bergman A, Drews RE. Purpose of admission and resource use during cancer hospitalisations. Health Care Financing Review 1991;13 $29-40$.

16 Dicing with death rates [Editorial]. Lancet 1993:341: 1183-4.

17 Smith P. Outcome related performance indicators and organisational control in the public sector. British foumal of Management 1993;4:135-51.

18 Vickers N, Pollock A. Incompleteness and retrieval of case notes in a case note audit of colorectal cancer. Quality in Health Care 1993:2:170-4.

19 Gulliford MC, Petruckevitch A, Burney PG. Hospital case notes and medical audit: evaluation of non-response.

20 Cohen BB, Pokras R, Meads MS, Krushat WM. How will diagnosis-related groups affect epidemiological research? Am ₹ Epidemiol 1987;126:1-9.

21 Clarke A, Tinsley P. Completed consultant episodes and hospital discharge. BMF 1992;304:990.

22 Buck N, Devlin HB, Lunn JN. The report of a confidential enquiry into perioperative deaths. London: Nuffield Provincial Hospitals Trust and King's Fund, 1987.

23 Kassirer JP. The use and abuse of physician profiles. $N \mathrm{Engl}$ f Med 1994;330:634-6. 